\title{
The Practical Knowledge of a Fine Arts Supervisor in Educational Change: A Case Study Rita Irwin
}

Change is a constant expectation placed upon teachers, students and administrators in our schools, particularly as they implement new art curriculum guidelines. A key actor in this scenario is the consultant, change agent, or supervisor, as they are referred to in various school districts. These individuals are often responsible for all grade levels and all facets of program or specific subject matter development, implementation, evaluation, material and human resource acquisition. Research has shown that these actors are a critical factor in the successful implementation of a new curricula. Teachers need theoretical and practical assistance in interpreting and implementing new curriculum guidelines (Crandall \& Loucks, 1983; Berman \& McLaughlin, 1975; Fullan, 1982).

Much of this research characterizes consultants and supervisors as being "curriculum managers": they are described according to the delineation of fragmented skills, functions, and roles from a very technological perspective (Havelock, 1973; Butler \& Paisley, 1978; Leithwood, 1982). The remaining literature investigates implementation through inservice and consulting from a more cultural perspective. The authors are concerned with the teacher-consultant dialogical relationship and prefer to characterize the consultant as colleague or co-participant (Aoki, et al, 1984). What this body of literature does not address is the 
experiential knowledge of supervisors. Conspicuously absent is a research study looking from the insider's perspective at the lifeworld of an art supervisor. This study does just that.

Recognizing this deficiency in the field caused me to look to other current literature dealing with the experiential knowledge of teachers. Rather than assuming teachers possess experience, this literature asserts that teachers acquire a unique knowledge of beliefs, intents, purposes and values that guides their practice. More specifically, it operates from a dialectical relationship between theory and practice. In this way theory is only valid so long as it is appropriate and usable in practice. Elba (1983) referred to this as "practical knowledge" and since it was oriented to individuals, it is better referred to as "personal practical knowledge."

Supervisors who come to their positions as master teachers in a given subject area obviously bring with them their own practical knowledge as teachers. But what happens as they also assume some administrative duties and responsibilities? Specific training for these roles is nearly nonexistent. What often occurs is on the job learning, ironically during a very short two to three year term. This becomes problematic if we accept what Sternberg and Caruso (1985) claim, that success in a job is a direct result of having more practical knowledge for that particular role. If we consider that supervisors may have practical knowledge different from a teacher's practical knowledge because of the addition of administrative responsibilities, then we might ask how this knowledge is different. More 
specifically, what would the practical knowledge be like for an art supervisor regarding educational change?

To research this problem, I chose to do a single case study of an exemplary fine arts supervisor whose strength was in art education. This ethnographic style of research allowed me to shadow Ruth, as I shall refer to her, for a four month period during the school year. In this way, I acted as a participant-observer in all of her activities ranging from observing art inservice sessions with elementary and secondary art teachers, to supervisors' meetings, principals' meetings, and to demonstrationteaching lessons. I listened to speeches she gave and I was on hand during the ordering of materials, answering requests, and the multitude of one-on-one interactions with many people. These observations offered me an in-depth look at the lifeworld of an art supervisor.

From an assortment of field notes, documents, interviews, informal and formal observation protocols, I proceeded to analyze the date inductively while recognizing my grounding in the literature of practical knowledge. From the initial round of analysis I have been able to categorize the five content areas of her practicalknowledge. They are: subject matter, instruction, milieu, curriculum implementation and self. These are reflective of the five commonplaces denoted by Schwab in practical knowledge with the inclusion of curriculum implementation rather than development (though the latter is accounted for within implementation). From there I looked for the various contexts or ways this knowledge was framed, and found these categories: theoretical, 
experiential, social, situational, personal, and political. It was here that I added the political orientation as a substantive context in which the supervisor works and comes to use some of her practical knowledge. In the literature addressing a teacher's practical knowledge, political awareness is only briefly mentioned within the milieu of the school and school system. This addition of the political context is a strong difference for the supervisor since she perceives herself at the interface between teachers and administrators. This becomes more potent if we recognize that technological and cultural perspectives tend to characterize the literature on supervisory roles in curriculum implementation. The political perspective is recognized by House (1981) as constituting a conflict rather than a consensus of interests between power, authority, and competition. It is led by an image of negotiation. Ruth's practical knowledge addresses the conflict, or rather the dialectic between several opposing images of power.

To date, this research has uncovered some fascinating guiding images by this exemplary figure. Connelly and Clandinin (n.d.) consider the image as a kind of knowledge embodied in a person and connected with the individual's past, present, and future. Images emerge from imaginative processes, acting as a glue to bind together a person's diverse experiences, creating personally meaningful and practically useful patterns.

Ruth is guided by two sets of images. One deals with the notion of the cycle of power and empowerment with teachers, and the other deals 
with recognizing the images the bureaucracy works from, or in other words, images of power and control. Ruth's images regarding the empowering of teachers can be found in such guiding images in her practical knowledge as "community," "the colleagual model," and "dance partners." Each of these reflect her attention to leading and responding to the needs of the teacher while assuming everyone is worthy of liberation from their taken-for-granted assumptions. Another image is "the parable of the sower of seeds" which portrays her as having patience, determination, and dedication toward slow change, and toward inviting everyone to participate all the time, even though only a few will choose to do so. Principles of "when any two people come together both should grow," "give more to a few rather than a little to a lot," and to "make sure the conditions are right so they are capable of giving," suggest further attention to individual teachers, their particular needs, desires, values, and biographies. There is an emotional coloring of caring, believing, trusting, and nurturing. It is brought together in the principle, "to empower other people is the more powerful way to act."

The other set of images reflects her practical knowledge of bureaucratic control and educational stability. The image of the "procrustean bed" metaphorically portrayed her concern for senior administration who foolishly applied rules and regulations to every situation. The images she held toward bureaucracy were of a very different nature than those previously described. Ruth saw "the school system as having a life of tis own," an inanimate life perhaps, but a life that dictated a 
certain shadow world of paper to justify every move. It was here that the image of getting "caught between the real world and the shadow world" portrayed the oppositions in her practical knowledge, and thus the dialectical interface between the two sets of images of teacher power and empowerment and bureaucratic power and control.

These oppositions are generally felt in the literature on implementation. Werner (1987) has described two metaphoric statements that illustrate these polarities. The producer-consumer metaphor talks of consumers as passive receivers. It deals with the product of curriculum: how marketed, how financed, how used. If the curriculum implementation were not successful, one of those factors would be at fault. This viewpoint serves administrative interest through greater control of implementation activities. According to this metaphor, teachers are taught how to carry out someone else's decisions on the assumption that the decisions are best for all concerned.

The colleagual metaphor is the opposite of that just discussed. Implementation does not automatically occur because of someone else's prescription of content and methodology. In the colleagual metaphor, teacher interpretations are a result of dialogue between teachers and supervisors since their combined knowledge and experiences are critically shared. In this way teachers are given the power to define their own practice within particular contexts.

Resolving the oppositions between these two metaphors becomes the dialectical interface between two forms of power and control found in 
Ruth's practical knowledge. Given that Ruth's supervisory practical knowledge differs fundamentally from a teacher's practical knowledge with the addition of a political context, this dialectical relationship presents a significant conflict supervisors or consultants must resolve. It also suggests that curriculum implementation may be essentially a political act (Aoki, et. al, 1984; House, 1981).

Ruth's style (Favaro, 1984) as supervisor may be most often viewed as a "colleague" when she sought change through dialogue with individual teachers. However, given the needs of teachers, Ruth also acted as a "co-participant" when she attempted to critically raise the consciousness of others, or as an "expert" when teachers or administrators needed specific directives in order to control the quality of instruction.

This study has contributed to the existing knowledge of supervisors through the description and interpretation of an exemplary fine arts supervisor's role in educational change. More specifically, the study has contributed to the literature of practical knowledge through its comparison of teachers' and supervisors' practical knowledge. In so doing, many implications come into focus. Several critical ones deal with questioning the common practice of hiring "master" teachers as consultants and supervisors for a short two or three year terms, only to return them to the classroom afterwards. Given the findings in this study, it would be fallacious to assume "master" teachers will necessarily be suitable to the role of supervisor. What's more, since practical knowledge is essentially experiential knowledge gained over time, at the point when consultants 
have acquired adequate practical knowledge, their contracts may be expiring. Finally, returning a consultant to the classroom may cause a disjuncture in the basic structure of one's practical knowledge, and thus, frustration for the individual.

Ruth's style as a supervisor acting as a colleague with teachers in educational change has made her, in my opinion, an exemplary figure in the field. More specifically however, this case study has offered the field an in-depth look at the consistency of one supervisor's practical knowledge as well as the apparent dialectical oppositions embedded within the role of supervisor. We can only benefit from such a portrayal, as we come to appreciate the unique practical knowledge necessary for supervisors to help teachers in colleagual relationships.

\section{References}

Aoki, T T., Carson, T. R., \& Favaro, B. J. (1984). Understanding situational meanings of curriculum in-service acts: Implementing, consulting, inservicing. (Curriculum praxis monograph series no. 9). Edmonton: University of Alberta, Department of Secondary Education.

Berman, P. \& McLaughlin, M. (1975). Federal programs supporting educational change: A findings in review. (Vol. IV). Santa Monica, CA: Rand Corporation.

Butler, M. \& Paisley, W. (1978). Factors determining roles and functions of educational linking agents. San Francisco: Far West Laboratory.

Connelly, M. \& Clandinin, D. J. (n.d.). Teachers' personal practical knowledge: Image and narrative unity. The University of Calgary and the Ontario Institute for Studies in Education and The University of Toronto.

Elbaz, F. (1983). Teacher thinking: A study of practical knowledge. London: Croom Helm.

Favaro, B. J. (1984). Re-searching the meanings of consulting in teacher 
inservice education. In T. T. Aoki, T. R. Carson, B. J. Favaro, Understanding situational meanings of curriculum in-service acts: Implementing, consulting, inservicing. (Curriculum praxis monograph series no. 9). (pp. 43-55). Edmonton: University of Alberta, Department of Education.

Fullan, M. (1982). The meaning of educational change. Toronto: OISE Press.

Havelock, R. G. (1973). The change agent's guide to innovation in education. Englewood Cliffs, NJ: Educational Technology Publications.

House, E. (1981). Three perspectives on innovation: Technological, political, and cultural. In R. Lehming \& M. Kane (Eds.). Improving schools: Using what we know. Beverly Hills, CA: Sage. pp. 17-41

Leithwood, K. A. (1982). Studies in curriculum decision-making. Toronto: OISE Press.

Schwab, J. J. (1969). The practical: A language for curriculum. School Review, 78, (1), pp. 1-23.

Sternberg, R. J. \& Caruso, D. R. (1985). Practical modes of knowing. In E. W. Eisner (Ed.). Learning and teaching: The ways of knowing. 84th Yearbook of the National Society for the Study of Education, Part II. Chicago: University of Chicago Press. pp. 133-158.

Werner, W. (1987). Training for curriculum implementation. Pacific Education, 1 (1), pp. 40-53. 